\title{
Warty dyskeratoma
}

INSERM

\section{Source}

INSERM. (1999). Orphanet: an online rare disease and orphan drug data base. Warty

dyskeratoma. ORPHA:69745

A rare, benign, epidermal disease characterized by a solitary, asymptomatic, verrucous, skin-coloured to red-brown papule or nodule, which contains a central pore and keratotic plug, occuring most frequently on the scalp, face and neck (rarely, in the mouth, under the nail plate or on the mons pubis). Occasionally, lesions may be multiple and/or pruritic. Histologically, a well-circumscribed, cup-shaped, keratin-filled invagination, with prominent acantholytic dyskeratosis, suprabasilar clefts and villi projecting into the clefts, is observed. 